\title{
Arthritis in Down's syndrome is still being missed
}

\section{Cruikshank*1, A Tunc ${ }^{2}$, J Walsh ${ }^{3}$, P Galea ${ }^{2}$, J Davidson ${ }^{2}$ and J Gardner- Medwin ${ }^{2}$}

\author{
Address: ${ }^{1}$ Royal Hospital for Sick Children, Edinburgh, UK, ${ }^{2}$ Royal Hospital for Sick Children, Glasgow, UK and ${ }^{3}$ Royal Alexandra Hospital, \\ Paisley, UK \\ * Corresponding author
}

from I5th Paediatric Rheumatology European Society (PreS) Congress

London, UK. 14-17 September 2008

Published: 15 September 2008

Pediatric Rheumatology 2008, 6(Suppl I):P54 doi:I0.II86/I546-0096-6-SI-P54

This abstract is available from: http://www.ped-rheum.com/content/6/SI/P54

(c) 2008 Cruikshank et al; licensee BioMed Central Ltd.

\section{Background}

Children with Down's syndrome are known to develop inflammatory arthritis with a prevalence thought to be greater than the general population [1]. Despite this, the diagnosis is still being overlooked leading to delayed treatment and poor outcomes.

\section{Cases}

We describe 8 cases, 4 females with an age range of $4.2-$ 15.6 (mean 9.3) years at diagnosis. Time from symptom onset to diagnosis ranged from $0.9-8.7$ (mean 3.3) years, despite attending up to 16 (mean 6.2) clinics with documented symptoms and signs of arthritis. Misdiagnoses included developmental delay, soft tissue injury, hypermobility, multiple epiphyseal dysplasia and behavioural problems. All had a clear clinical diagnosis of polyarticular arthritis and four where non-weight bearing at first contact with paediatric rheumatology. Two patients had psoriasis. One patient had psoriatic nail changes. Five had a family history of rheumatological disease. All were antinuclear antibody negative. All were treated with intraarticular steroid injections. All were offered methotrexate and five clinically responded. Of the three who did not tolerate methotrexate, two were offered and improved with etanercept.

\section{Conclusion}

Diagnosis of arthritis in children with Down's syndrome is still significantly delayed compared to other children presenting with inflammatory arthritis. In our cohort, response to treatment was similar to children with juve- nile idiopathic arthritis (JIA). Current evidence suggests response to treatment in JIA is optimal when commenced early. Many of this cohort had significant joint damage and disability by time of diagnosis. Delays in diagnosis are contributing to unnecessary disability in this group of children.

\section{References}

I. Padmakumar B, Evans Jones LG, Sills JA: Is arthritis more common in children with Down syndrome? Rheumatology 2002, $41: 1191-1193$. 